\title{
A renewed focus on supply chain risk management
}

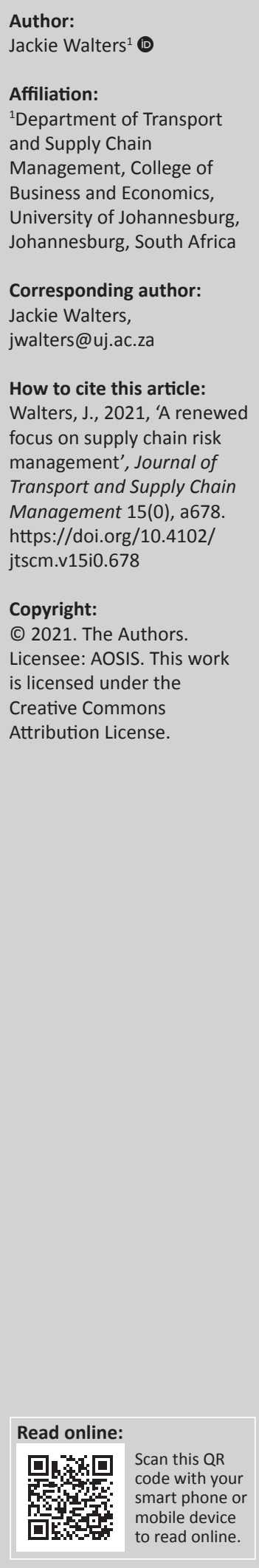

Worldwide supply chains depend on stable and reasonable forecastable demand and supply for goods and services to do what they do well - reduce inventory, deliver on a just in time basis, add value to products and services, and reduce costs. They are normally flexible and agile enough to weather risks such as wars, famine, droughts, unrest, regional trade issues and industrial action, and recover from these events in reasonable time. However, since the emergence of the coronavirus disease 2019 (COVID-19) and other unforeseen risks, supply chains have been facing somewhat of a perfect storm that has probably changed the way they operate in a very fundamental way.

The COVID-19 pandemic severely impacted economies throughout the world as most governments had various forms of lockdowns in an effort to contain the spread of the virus, thus disrupting normal demand and supply of products on a scale never seen before. Many employees were forced to work from home and had to become accustomed to online meetings and online shopping. An increase in online shopping created new distribution networks and disrupted physical in-shop purchases. Working from home also impacted the use of public transportation, both in the air and on the ground, with far-reaching consequences. However, cargo trade was generally allowed to continue; but various governmental measures to contain the spread of the virus such as port, airport and border closures, cargo decontamination, and skeleton staff affected the normal supply and distribution of products. In addition to the general impacts of COVID-19, there has been other international events that impacted supply chains, these include: the United States' hostility towards China, a cargo ship running aground in the Suez Canal impacting world trade for nearly a week, random port closures in China to deal with COVID-19 outbreaks, factory shutdowns in Vietnam, shipping container shortages and increased shipping costs, shortages of microchips because of, amongst others, a major micro chip plant fire in Japan, a drought in Taiwan, and increased consumer demand for electronic products.

South Africa had one of the strictest lockdown strategies in the world which had a devastating impact on the economy and society. Businesses were forced to sell only essential products, online shopping was forbidden for a period and extensive travel restrictions were imposed. In addition, provincial and international borders were closed for general travel for long periods. During the height of the first lockdown in South Africa, commuter bus companies experienced as much as an $80 \%$ drop in the demand for services, and 18 months later patronage still has to fully recover to pre-COVID-19 levels. The same rationale played itself out in the intercity and tour charter bus sectors. The closure of provincial borders for months on end resulted in some intercity bus operators ceasing business and tour/charter bus companies that are mostly reliant on international incoming tourist travel, closing up their businesses. The country's commuter rail system has also been extensively vandalised during lockdowns as adequate security was not maintained. It is estimated that the cost of restoring the commuter rail system to pre-COVID-19 levels will be in excess of R120 billion. Air travel in the country came to a virtual standstill for about 6 months forcing some airline companies into business rescue and bankruptcy. Throughout 2020 only limited national, regional and international air services were operating in the country as passengers avoided airlines for the fear of contracting COVID-19. Predictions are that international air travel will probably operate at between $25 \%$ and 30\% of pre-COVID-19 levels for some years to come.

There were also other unforeseen events in South Africa that impacted consumers, such as the extensive civil unrest experienced in Gauteng and KwaZulu-Natal in July 2021 that disrupted supply chains because of the closure of the N3 highway for nearly a week, the looting and burning of major warehouse facilities, and general disruption of product movements. In addition, there is extensive and continued vandalism of the rail network in South Africa affecting rail cargo movements. Poor management at Transnet Freight Rail has also resulted in massive tonnages of rail friendly cargo moving to road transport over the years resulting in a significant increase in 
road freight movements. On secondary roads, the effect has been devastating as the roads could neither cope with, nor were they designed for such high volumes of road freight. On major highways linking the main centres in South Africa, road freight is causing major bottlenecks and congestion. Poor port performance as a result of poor port management and the impact of COVID-19 on port operations has resulted in delayed shipments and ships by-passing ports thus adding to the cost of logistics as well as further uncertainty. South Africa also experienced cyber security issues at Transnet that resulted in the company declaring force majeure for its services at three crucial ports for about 10 days.

These events can be seen as inflection events that will have farreaching consequences for the broader supply chain community. Businesses had to rethink the role of their logistics personnel and logistics strategies as traditional just in time strategies led to empty shelves and bottlenecks. Many companies resorted to higher levels of inventory to cope with production and supply volatility in order to keep their supply chains operational. Evaluating the impact of unforeseen risks on supply chains have become the norm. To manage supply chain risks better, businesses are reconsidering long distance supply chains and the risks they pose, sourcing too much from one country or a limited number of suppliers (reverting to multi-sourcing) and reconsidering onshoring of production facilities.

Consumer behaviour has also changed as online shopping has taken off. Traditional retailers have been forced to increasingly accommodate online sales and have introduced distribution strategies in response. In major centres in South Africa, one retailer now offers delivery services within $60 \mathrm{~min}$ with the consumer being kept informed in real time as the picking takes place in the store about product availability and product alternatives. It is foreseen that the high demand for online retailing will taper off somewhat as the economy returns to normality and consumers are able to move around freely, but retailers will be well advised to keep on introducing new innovative ideas to retain and increase online sales.

The extensive disruptions that supply chains have experienced over the last 18 months have also focused the attention on the curricula of many universities and business schools as most did not have a critical focus on supply chain risk as part of their teaching and research programmes. Curriculums will have to be adapted to identify potential known and unknown supply chain risks, explore new risk mitigation strategies (de-risking strategies), new supply chain business models, and a renewed focus on supply chain flexibility. Case studies on how manufacturers, suppliers, retailers and transportation service providers coped with this level of uncertainty will certainly provide some insight into how to deal with these matters in future.

The results of the COVID-19 pandemic and other supply chain risks will be that supply chains will, over time, adapt to these circumstances and be better geared to deal with risk resulting in improved levels of service. It is, however, important that the lessons learned from these crises be conveyed widely so that supply chain role players become closer aligned and attuned to potential risk and risk mitigation strategies to improve service and product availability. 